\title{
SYNTHESIS AND CHARACTERIZATION OF MUC-1 FUNCTIONALIZED GOLD NANOPARTICLES
}

\section{CRISTIAN T. MATEA ${ }^{a}$, TEODORA MOCAN ${ }^{a, b *}$, FLAVIU TABARAN ${ }^{a, c}$, TEODORA POP ${ }^{d}$, OFELIA MOSTEANU ${ }^{\mathrm{d}}$, LUCIAN MOCAN ${ }^{\mathrm{a}, \mathrm{e}}$, CLAUDIU ZDREHUS}

\begin{abstract}
Gold nanoparticles have been functionalized with the biologically active MUC-1 peptide conjugated to $\mathrm{KLH}$ and the obtained bionanostructure was characterized using an array of techniques such as: UVVis and ATR-FT-IR spectroscopy, dynamic light scattering (DLS) and atomic force microscopy (AFM). A $54 \mathrm{~nm}$ monodisperse bio-nanostructure with high aqueous stability was obtained.
\end{abstract}

Keywords: gold nanoparticles, functionalization, MUC-1 peptide

\section{INTRODUCTION}

Metal nanoparticles and especially gold nanoparticles (GNPs) have attracted a lot of interest from the scientific community due to their unique properties such as: large surface-to-volume ration, optoelectronic properties, rich functionality, low toxicity and high biocompatibility [1, 2]. Recent advances in the fields of nanoparticles synthesis and functionalization resulted in novel medical applications $[3,4]$. One area of biomedical research in which GNPs have center stage is the development of carriers for cellular delivery of drugs, proteins and non-cell-penetrating peptides [5-8].

a Department of Nanomedicine "Octavian Fodor" Gastroenterology Institute, Cluj-Napoca, Romania

' Department of Physiology, "Iuliu Hatieganu" University of Medicine and Pharmacy, Cluj-Napoca, Romania

${ }^{c}$ Department of Pathology, Faculty of Veterinary Medicine, University of Agricultural Sciences and Veterinary Medicine

d 3rd Gastroenterology Department "Iuliu Hatieganu" University of Medicine and Pharmacy, ClujNapoca, Romania

e 3rd Surgery Clinic "Iuliu Hatieganu " University of Medicine and Pharmacy Cluj-Napoca Romania

*Corresponding author: teodora.mocan@umfcluj.ro 
Keyhole limpet hemocyanin (KLH) is a high molecular weight coppercontaining protein which can act as a nonspecific immune stimulant [9]. A study conducted by $\mathrm{Kim}$ et al. showed that there is a strong correlation between the antibodies induced against peptide antigen MUC1 and carbohydrate antigen GD3 with different immunological adjuvants and the strength of Interferon- $y$ release against KLH [10].

We have previously showed that a MUC-1 protein fragment attached on the surface of gold nanoparticles can elicit the activation of peritoneal macrophages as a possible anticancer vaccine [11]. In our present study we have functionalized gold nanoparticles with the biologically active MUC-1 peptide which is in turn conjugated to $\mathrm{KLH}$ and characterized the obtained bio-nanostructure using an array of techniques such as: UV-Vis and ATR-FT-IR spectroscopy, dynamic light scattering (DLS) and atomic force microscopy (AFM).

\section{RESULTS AND DISCUSSION}

When developing a novel bio-nanostructure a key aspect is its thorough characterization. An incomplete characterization of nanomaterials limits scientific understanding and slows the development and transfer of new technologies [12]. Citrate capped GNPs and MUC-1 $1_{\text {pep }}$ functionalized GNPs were characterized by means of UV-Vis, ATR-FT-IR, DLS and AFM techniques.

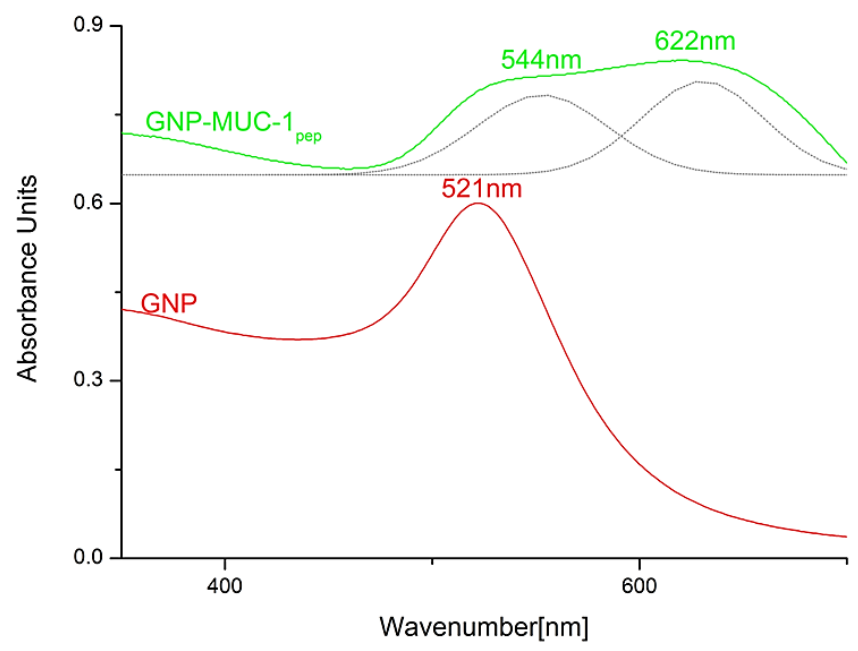

Figure 1. UV-Vis spectra of GNPs (red line) and GNP-MUC-1 $1_{\text {pep }}$ (green line); the grey dotted lines represent the deconvoluted sub bands assigned to the $\mathrm{Au}^{0}$ surface plasmon resonance band(544nm) and KLH protein (622nm). 
Figure 1 presents the UV-Vis spectra for the citrate capped gold nanoparticles (GNPs -red line) and for the MUC-1pep functionalized gold nanoparticles (GNP-MUC-1 $1_{\text {pep }}$ - green line). In the case of GNPs the absorption peak registered at $521 \mathrm{~nm}$ is attributed to the surface plasmon resonance (SPR) band of gold nanoparticles $[13,14]$. The GNP-MUC-1pep sample registered a broad peak in the region 500-650nm, after spectral deconvolution the resulting two sub bands (grey dotted lines) at 544nm and $622 \mathrm{~nm}$ were assigned to the gold nanoparticle SPR and the oxidized form of the KLH protein, respectively.

The size of both GNP and GNP-MUC-1 $1_{\text {pep }}$ were measured by dynamic light scattering. DLS size distribution curves are presented in figure 2, both samples were monodispersed and presented good stability at room temperature and at $37^{\circ} \mathrm{C}$. The increase in size suggested by the bathochromic shift of the SPR peak of colloidal gold after functionalization is also confirmed by the DLS measurements. The citrate capped gold nanoparticles registered a mean hydrodynamic size of $17 \mathrm{~nm}$, while de MUC-1 $1_{\text {pep }}$ functionalized GNP recorded a mean diameter of $62 \mathrm{~nm}$ and a polydispersity index of 0.288 .

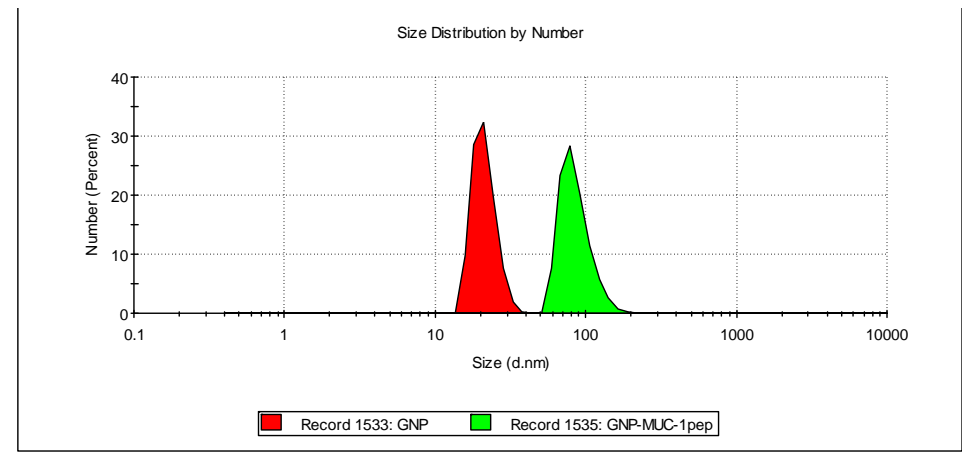

Figure 2. DLS size distribution curves for GNP (red) and GNP-MUC-1 $1_{\text {pep }}$ (green) samples.

The results from the ATR-FT-IR spectroscopy measurements conducted on GNP and GNP-MUC-1pep samples are presented in figure 3. The citrate capped GNPs presented IR adsorption bands centered at 1392 and $1576 \mathrm{~cm}^{-1}$, which are attributed to the symmetric and antisymmetric stretching of $\mathrm{COO}^{-}$of citrate ions [15-17]. GNP-MUC-1 $1_{\text {pep }}$ presented IR adsorption bands at 1730 and $1599 \mathrm{~cm}^{-1}$ which were attributed to the amide I and amide II vibrations from the KLH-MUC- $1_{\text {pep }}$ conjugate layer present on the surface of the GNPs [15]. Thus, the successful functionalization of the citrate gold nanoparticles with the MUC-1 peptide is confirmed by comparing the IR spectra of the GNP and GNP-MUC-1 $1_{\text {pep }}$ samples. 


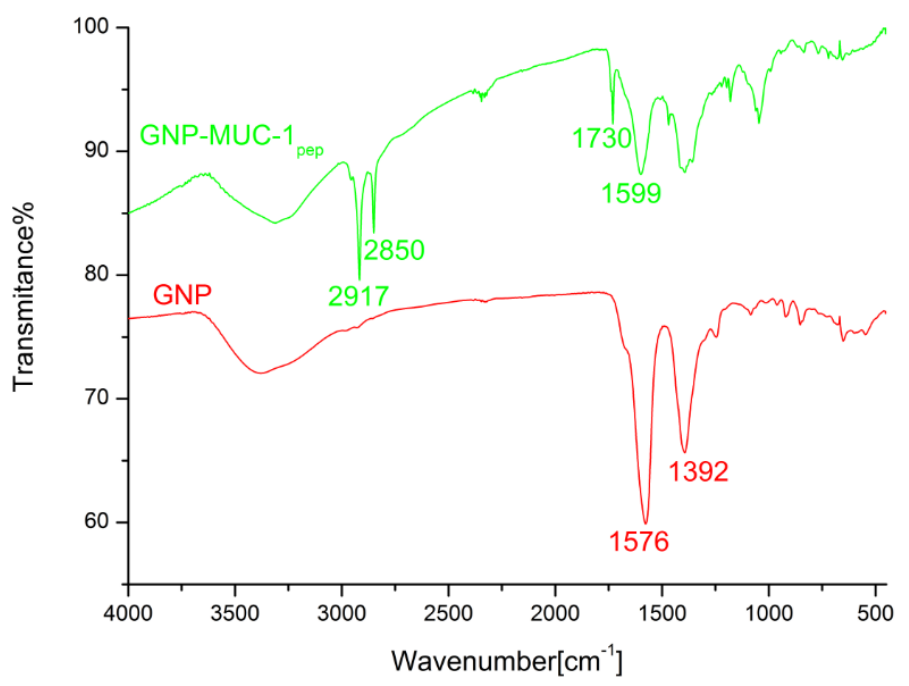

Figure 3. ATR-FT-IR spectra for GNP (red) and GNP-MUC-1 $1_{\text {pep }}$ (green)samples

In order to further investigate the size and the shape of the MUC-1pep functionalized gold nanoparticles AFM measurements were conducted. Figure 4.A. depicts a 2D representation, while figure 4.B. shows a 3D representation of a single GNP-MUC-1pep nanoparticle, in both cases the spherical shape of the bio-nanostructure can be observed. GNP-MUC-1 $1_{\text {pep }}$ presented an average diameter of $\sim 54 \mathrm{~nm}$, as measured by AFM, while DLS measurements on the same sample provided a mean diameter of $\sim 62 \mathrm{~nm}$. This can be explained by the fact that the DLS technique provides a mean hydrodynamic diameter of GNPs surrounded by the KLH protein-MUC-1 $1_{\text {pep }}$ and the solvation layers [15].
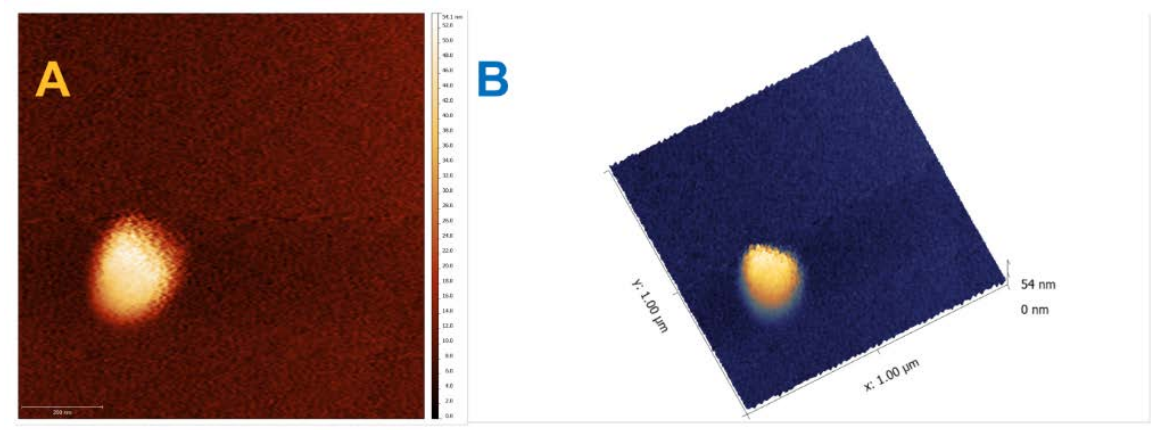

Figure 5. AFM image of GNP-MUC-1 pep $_{\text {: }}(\mathrm{A})$ 2D image; (B) 3D image. 


\section{CONCLUSIONS}

Gold nanoparticles were functionalized with a KLH-MUC-1 peptide conjugate yielding a 54nm monodisperse bio-nanostructure with high aqueous stability. The characterization of the obtained material involved UV-Vis and FTIR spectroscopies in order to confirm the success of the functionalization step. The dynamic light scattering and atomic force microscopy techniques were employed to determine the size and shape of the GNPs prior and after functionalization. Investigations into the biological interactions of this novel bionanostructure are required in order to determine its potential for medical applications.

\section{EXPERIMENTAL SECTION}

$\mathrm{HAuCl}_{4}(\geq 99.9 \%)$, tri-sodium citrate ( $\geq 99 \%$ ), DL-dithiotreitol (DTT) $(\geq 99 \%)$ and $\mathrm{NaH}_{2} \mathrm{PO}_{4}$ were purchased from Sigma-Aldrich ${ }^{\mathrm{TM}}$ (Darmstadt, Germany). MUC-1 peptide, aminoacid one letter code - TSAPDNRPALGSTA, attached to keyhole limpet hemocyanin $(\mathrm{KLH})$ protein was purchased from Abcam (Austin, USA). All reagents were used as received, without further purification.

Citrate capped gold nanoparticles (GNPs) were obtained by employing a modified Turkevich method. Briefly, 9.8mg HAuCl 4 were dissolved in $20 \mathrm{~mL}$ distilled water and heated to $100^{\circ} \mathrm{C}$, to this, $2 \mathrm{~mL}$ sodium citrate $(20 \mathrm{mg} / \mathrm{mL})$ were added. The reaction was allowed to continue for 2 hours under reflux and continuous stirring, during this stage the solution turned from pale-yellow to dark-red. For the functionalization of the GNPs with KLH-MUC-1 conjugate, a $100 \mu \mathrm{L} \mathrm{KLH}-M U C-1$ pep solution $(1 \mathrm{mg} / \mathrm{mL})$ was mixed with $300 \mu \mathrm{L}$ DTT $100 \mathrm{mM}$ $(\mathrm{pH}=8.5)$ and was added to $10 \mathrm{~mL} \mathrm{GNP}$ solution and kept under vigorous agitation for 5 minutes. The obtained GNP-MUC-1pep was subjected to a centrifugation step at $15000 \mathrm{RPM} / 30 \mathrm{~min}$. and the resulting pellet was redispersed in $\mathrm{H}_{2} \mathrm{O}$ bidist. The purified GNP-MUC-1 $1_{\text {pep }}$ sample presented good stability over several weeks, at room temperature and at $4^{\circ} \mathrm{C}$.

UV-Vis spectroscopy was performed on the samples with a Shimadzu UV-1800 spectrophotometer. The GNP and GNP-MUC-1 $1_{\text {pep }}$ spectras were recorded from $800 \mathrm{~nm}$ to $200 \mathrm{~nm}$ with a spectral resolution of $0.5 \mathrm{~nm}$. OriginLab ${ }^{\circledR}$ software 7.0 was used to normalize all recorded spectras.

Dynamic light scattering (DLS) measurements were performed with a Nano S90 instrument (Malvern Instruments, Westborough, UK) at $25^{\circ} \mathrm{C}$ at $90^{\circ}$ scattering angles. 
Universal attenuated total reflectance Fourier transform infrared spectroscopy (ATR-FT-IR) measurements were conducted on a Perkin-Elmer Spectrum Two ${ }^{\circledR}$ instrument equipped with an UATR single reflection diamond. Spectral data processing and baseline corrections were done using the Spectrum $10^{\mathrm{TM}}$ software.

Atomic force microscopy (AFM) data were recorded with the aid of a Workshop TT-AFM ${ }^{\circledR}$ (AFMWorkshop, CA, USA) operated in vibrating mode using super-sharp ACTA-SS cantilevers (AppNano, CA, USA). The recorded data was further processed with the Gwyddion ${ }^{\circledR} 2.36$ software.

\section{ACKNOWLEDGMENTS}

This work was supported by the Romanian National Authority for Scientific Research and Innovation, CNCS-UEFISCDI, project numbers PNIII-P2-2.1-BG-2016-0446, PN-III-P1-1.1-PD-2016-1831 and PN-III-P1-1.1-TE2016-2161.

\section{REFERENCES}

1. N. Elahi; M. Kamali; M.H. Bachersad, Talanta 2018, 184, 537.

2. A. Gharatape; R. Salehi, European Journal of Medicinal Chemistry 2017, 138, 221.

3. L. Mocan; F.A. Tabaran; T. Mocan; T. Pop; O. Mosteanu; L. Agoston-Coldea; C. T. Matea; D. Gonciar; C. Zdrehus; C. Iancu, International Journal of Nanomedicine 2017, 12, 2255.

4. T. Mocan; C.T. Matea; T. Pop; O. Mosteanu; A.D. Buzoianu; S. Suciu; C. Puia; C. Zdrehus; C. Iancu; L. Mocan, Cellular and Molecular Life Sciences 2017, 74 (19), 3467.

5. S. Bathia, Nanoparticles Types, Classification, Characterization, Fabrication Methods and Drug Delivery Applications. In Natural Polymer Drug Delivery Systems, Springer, Cham: 2016.

6. B. Duncan; C. Kim; V.M. Rotello, Journal of Controlled Release 2010, 148 (1), 122.

7. C.T. Matea; T. Mocan; F. Tabaran; C. Iancu; L. Mocan, Journal of Nanobiotechnology 2015, 13 (41).

8. Z.P. Xu; Q.H. Zeng; G.Q. Lu; A.B. Yu, Chemical Engineering Science 2006, 61 (3), 1027.

9. D.W. McFadden; D.R. Riggs; B.J. Jackson; A. Ng; C. Cunningham, The American Journal of Surgery 2007, 193 (2), 284. 
10. S.K. Kim; G. Ragupathi; C. Musselli; S.-J. Choi; Y.S. Park; P.O. Livingston, Vaccine 2000, 18, 597.

11. T. Mocan; C. Matea; F. Tabaran; C. Iancu; R. Orasan; L. Mocan, Journal of Cancer 2015, 6 (6), 583.

12. D.R. Baer; M.H. Engellhard; G E. johnson; J. Laskin; J. Lai; K. Mueller; P. Munusamy; S. Thevuthasan; H. Wang; N. Washton, Jornal of Vacuum Science and Technology A 2013, 31 (5).

13. L. Shang; Y. Wang; J. Jiang; S. Dong, Langmuir 2007, 23, 2714-2721.

14. Y. Wang; Y. Ni, Talanta 2014, 119, 320.

15. G. Mandal; M. Bardhan; T. Ganguly, Colloids and Surfaces B: Biointerfaces 2010, 81 (178-184).

16. J. Park; J. Shumaker-Parry, Journal of the American Chemical Society 2014, 136, 1907-1921.

17. X. Zou; E. Ying; S. Dong, Nanotechnology 2006, 17 (4758-4764). 